\title{
Evaluation of the Fiber Stress Distribution in Aramid/Epoxy Model Composite Using Micro-Raman Spectroscopy and FEM Analysis*
}

\author{
Kazuto TANAKA $^{* *}$ Kohji MINOSHIMA $^{* * *}$ and Hideo YAMADA ${ }^{* * * *}$ \\ **Doshisha University, \\ 1-3 Miyakodani, Tatara, Kyotanabe, Kyoto, 610-0321, Japan \\ E-mail: ktanaka@mail.doshisha.ac.jp \\ ${ }^{* * *}$ Osaka University, \\ 2-1, Yamadaoka, Suita, Osaka, 565-0871, Japan \\ E-mail: k-minoshima@mech.eng.osaka-u.ac.jp \\ ****Kyoto University, \\ Yoshida-Honmachi, Sakyo-ku, Kyoto, 606-8501 Japan
}

\begin{abstract}
A single-fiber pull-out model composite for an aramid/epoxy system was specially designed to measure the stress distribution of the aramid fiber embedded in the matrix using micro-Raman spectroscopy. The stress transfer length of the fiber obtained was about 400-500 $\mu \mathrm{m}$, which was equal to the result of FEM analysis. Just after the initiation and propagation of the fiber/matrix interfacial debonding, the fiber was broken, and the fiber in the matrix had the axial tensile residual stress. The tensile residual axial stress showed the maximum at around the tip of the interfacial debonding. The stress was reduced after the specimen was kept in air at $80^{\circ} \mathrm{C}$ for $44 \mathrm{~h}$, and it became almost equal to zero after being immersed in deionized water at $80^{\circ} \mathrm{C}$ for $44 \mathrm{~h}$. This behavior agreed with the result of FEM analysis, in which the friction coefficient was introduced in the fiber/matrix interface. The axial residual stress was caused by the friction between the fiber and matrix, due to the compressive stress acting between the resin and the fiber, which was caused by the difference of the coefficient of thermal expansion.
\end{abstract}

Key words: Composite Material, Reinforced Plastics, Finite Element Method, Interfacial Properties, Micro-Raman Spectroscopy, Pull-Out Test, Fiber Stress Distribution, Aramid Fiber, Friction

\section{Introduction}

Investigation of the fracture strength and fracture mechanism of the fiber/matrix interface is extremely important, because the mechanical properties of the fiber reinforced composites depend strongly not only on the properties of the fibers and the matrix but also on the fiber/matrix interfacial ones. To evaluate the mechanical properties of fiber/matrix interface, the tensile strength of unidirectional fiber composites loaded in the transverse direction to the fiber direction was used by many researchers ${ }^{(1)}$, because of easy testing method. However, the strength is governed not only by the interfacial strength but also by the mechanical properties of the matrix, and therefore the direct measurement of fiber/matrix interface by using a micro-composite is proper to obtain the mechanical properties of the interface itself $f^{(2)}$. Among the micro-composite tests including the single fiber compression test, the fiber fragmentation test, the fiber pull-out test, the fiber push-out

*Received 18 Jan., 2007 (No. T-04-1316) Japanese Original : Trans. Jpn. Soc. Mech. Eng., Vol. 71, №. 712, A (2005),

pp.1639-1645 (Received 16 Dec., 2004) [DOI: 10.1299/jmmp.1.364] 
test, etc., the fiber pull-out test is one of the popular methods to quantitatively evaluate the mechanical properties of the interface ${ }^{(2)}$. We carried out the single fiber pull-out tests to investigate the influence of water absorption on the interfacial properties of an aramid/epoxy composite ${ }^{(3)}$. In this study, however, the pull-out load, at which the unstable crack propagated through the total embedded fiber length, was used for the measure of the interfacial strength and the stress distribution along the fiber in the matrix was not clarified. Moreover to clarify the interfacial crack propagation and retardation under fatigue loading, it is extremely important to understand the stress distribution along the fiber close to the crack tip $^{(4)}$.

Recently, Raman spectroscopy gives a new and non-contact measuring tool to directly measure localized strain or stress. The technique to measure strain/stress is based on the fact that the Raman frequencies are strain/stress dependent. As the laser beam can be focused to a small diameter, strain/stress distribution of such as the fiber in a matrix can be measured in the spatial resolution of several micrometers. Using this technique, the stress transfer behavior $^{(5)(6)}$, interfacial degradation by water ${ }^{(7)(8)}$, stress relaxation by the broken fiber ${ }^{(9)}$ and the difference of the stress distribution before and after interfacial debonding ${ }^{(10)}$ were investigated. However the stress distribution after interfacial debonding under unloading condition, which is important for interfacial fatigue crack propagation behavior, has not yet been clarified. In this study, a single-fiber pull-out model composite for an aramid/epoxy system was specially designed and the difference of stress distribution along the fiber before and after the interfacial debonding was quantitatively measured by using Raman spectroscopy. Moreover the stress distribution before and after the fiber/matrix interfacial debonding was analyzed by FEM.

\section{Experimental procedure and FEM analysis}

\subsection{Specimen preparations and experimental procedures}

The technique to measure the stress of the fiber using laser Raman spectroscopy is based on the fact that the Raman frequencies are strain (stress) dependent. Therefore, using the calibration curves of the peak wavenumber of Raman spectrum vs stress of a fiber, the measured Raman peak wavenumber of the embedded fiber can be converted to an axial stress. In this investigation, the Raman spectra were obtained by means of a laser Raman micro spectrometer (JASCO Corporation, NRS-2000). The $514.5 \mathrm{~nm}$ line of an argon-ion laser was used and the laser beam was focused to a $1.5 \mu \mathrm{m}$ spot on the fiber by an optical microscope.

The aramid fiber used in this study was Kevlar 49 manufactured by Du Pont, USA. The fiber had an average diameter of $12 \mu \mathrm{m}$. To obtain the calibration curves, single-fibertensile specimens were prepared by following the recommended testing procedure as described in ASTM D3379/JIS R7601. Polyester thin film (Thickness: $100 \mu \mathrm{m}$ ) was used for a tab and a single fiber was glued to it, giving a gauge length of $12 \mu \mathrm{m}$. Quasistatic tensile tests were carried out by a tensile testing machine using an motorized stage (Sigma Koki Co. Ltd., SGPS20-20) with a load cell of $1 \mathrm{~N}$ capacity (Kyowa Electronic Instruments Co. Ltd., LTS-100GA), which was set on the measuring stage of the laser Raman micro spectrometer. The relationship between the peak wavenumber of Raman spectrum and stress applied to a fiber was measured to obtain the calibration curve.

The specimen construction for a single fiber pull-out specimen is shown in Fig. 1. An epoxy resin, Epikote 828 and curing agent Epicure Z (Japan Epoxy Resins Co. Ltd.) were used in 5:1 weight ratio. The resin was put on the center of the tab with a fiber, as illustrated in Fig. 1(a). Specimens were placed in an oven for two hours at $80^{\circ} \mathrm{C}$ and then for two hours at $150^{\circ} \mathrm{C}$. The epoxy resin remained on the tab after curing, and the fiber was embedded in the matrix between the position A and B shown in Fig. 1(b). The fiber 
embedded length was about $1.3 \mathrm{~mm}$ and the resin thickness between fiber/matrix interface and polyester tab was about $100 \mu \mathrm{m}$. Pull-out tests were performed using the above-mentioned tensile testing machine in the laser micro-Raman spectrometer. After chucking a specimen, the tab shown in Fig. 1(b) was cut and the load was applied to the fiber. Raman spectrum was measured along the fiber for both the embedded fiber and the free fiber at several stress levels, as shown in Fig. 2. In this study the stress of the fiber adopted was the nominal stress, which was calculated from the value of the load cell.

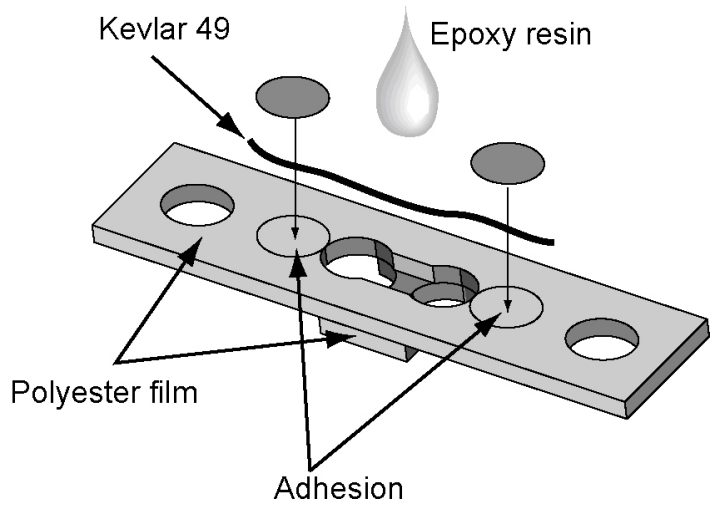

(a) Specimen construction.

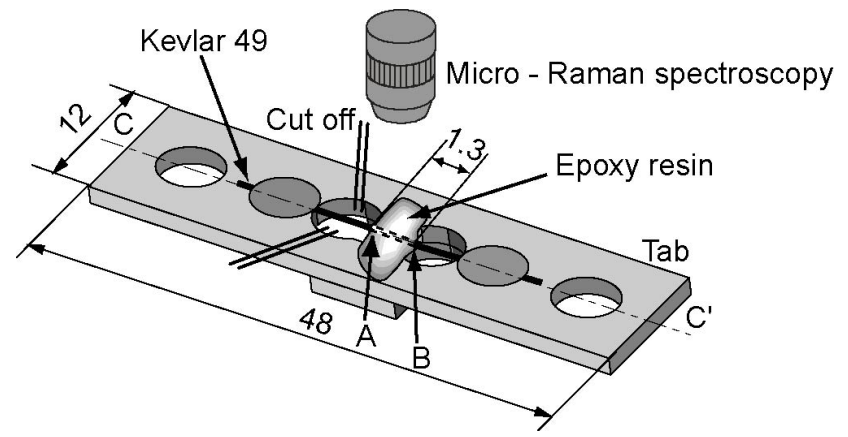

(b) Shape and dimensions of pull-out specimen. All dimensions are in $\mathrm{mm}$.

Fig. 1 Single fiber pull-out specimen.

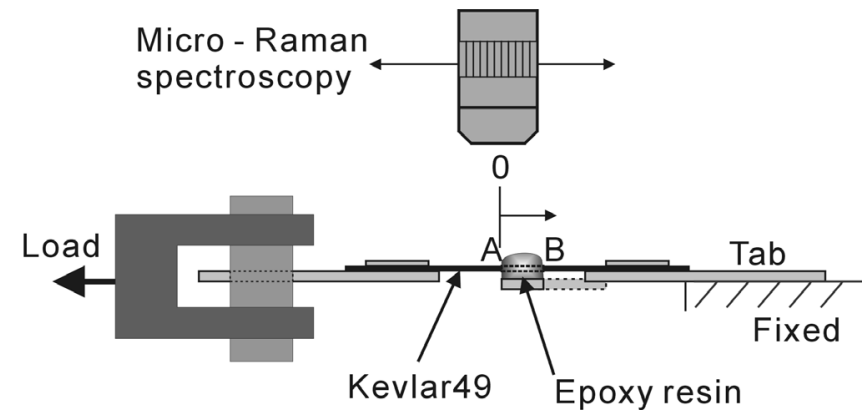

Fig. 2 Schematic drawing of the pull-out test procedure (C-C' cross section shown in Fig. 1(b)).

\subsection{FEM analysis}

FEM analysis was conducted using the commercial code ANSYS to estimate the stress distribution during the pull-out test and after fiber/matrix interfacial debonding. Specimen was simplified to the model shown in Fig. 3(a). A single fiber of $12 \mu \mathrm{m}$ in diameter was embedded in the cylindrical resin of $100 \mu \mathrm{m}$ in radius and $1300 \mu \mathrm{m}$ in length. Analysis was 
conducted using 2D model using eight-noded quadrilateral elements with and without the interfacial debonding of $200 \mu \mathrm{m}$ in length shown in Fig. 3(b). The mesh was finer close to the crack tip and the total numbers of the elements and nodes were 2228 and 6855 , respectively. The following boundary conditions were selected as shown in Fig. 3(b).

(a) the outer surface of the resin: displacement equal to zero in the y direction, coupling conditions in the $\mathrm{x}$ direction (all nodes has the same displacement)

(b) the center of the fiber: displacement equal to zero in the $\mathrm{x}$ direction

For FEM analysis, thermal expansion during specimen preparation, friction at the fiber/matrix interface and swelling expansion of resin were taken into account. Mechanical properties used in this analysis are shown in Table $1^{(11-13)}$. Friction coefficient $(\mu)$ and maximum friction stress $\left(\tau_{\max }\right)$ at the interface were estimated from the maximum friction load after debonding obtained by same fiber/matrix pull-out test ${ }^{(3)}$ and the fiber compressive stress to the radius direction caused by the thermal expansion of the resin during specimen curing. The value obtained were $\mu=0.6$ and $\tau_{\max }=11.9 \mathrm{MPa}$. Swelling of the resin in deionized water was set for $0.6 \%$ obtained at $80^{\circ} \mathrm{C}$ for 44 hours ${ }^{(3)}$ and the swelling of the fiber was neglected.

Analyzed steps are summarized as follows:

(1) Taking into account the thermal stress during resin curing: specimen was cooled from the curing temperature of $150^{\circ} \mathrm{C}$ to room temperature of $20^{\circ} \mathrm{C}$.

(2) Maximum fiber fracture stress of $2.65 \mathrm{GPa}$ was applied to the fiber, which was obtained by the fiber pull-out test.

(3) Taking into account the fiber fracture: applied fiber stress was fully unloaded.

(4) Considering the influence of conditioning in hot water at $80^{\circ} \mathrm{C}$ or dry air,

(a) the temperature of the specimen was changed from $20^{\circ} \mathrm{C}$ to $80^{\circ} \mathrm{C}$ and in the case of conditioning in hot water swelling expansion of the resin was applied.

(b) for both cases, the temperature of the specimen was cooled down from $80^{\circ} \mathrm{C}$ to $20^{\circ} \mathrm{C}$.

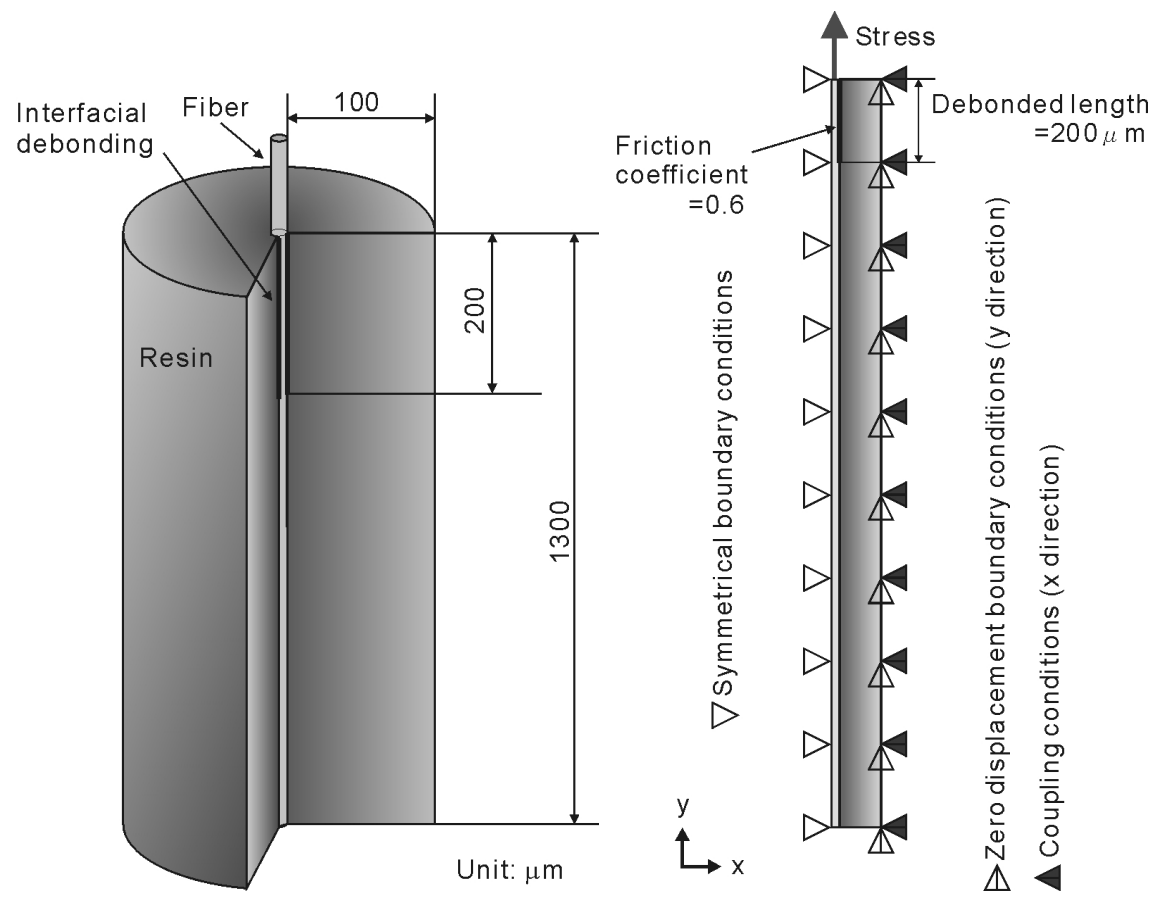

(a) Model of the specimen. (b) 2D model with boundary conditions.

Fig. 3 FEM model with interfacial debonding. 
Table 1 Mechanical properties of the fiber and resin ${ }^{(11)-(13)}$.

(a) Epoxy resin (Epikote828 + Epicure Z)

\begin{tabular}{|c|c|}
\hline Young's modulus & $2.48 \mathrm{GPa}$ \\
\hline Poisson's ratio & 0.4 \\
\hline $\begin{array}{c}\text { Coefficient of thermal } \\
\text { expansion }\end{array}$ & $60 \times 10^{-6}{ }^{\circ} \mathrm{C}^{-1}$ \\
\hline
\end{tabular}

(b) Fiber (Kevlar 49)

\begin{tabular}{|c|c|c|}
\hline \multirow{2}{*}{ Young's modulus } & $\mathrm{E}_{\mathrm{L}}$ & $129.6 \mathrm{GPa}$ \\
\cline { 2 - 3 } & $\mathrm{E}_{\mathrm{T}}$ & $2.49 \mathrm{GPa}$ \\
\hline \multirow{2}{*}{ Poisson's ratio } & $v_{\mathrm{LT}}$ & 0.62 \\
\cline { 2 - 3 } & $v_{\mathrm{TT}}$ & 0.31 \\
\hline \multirow{2}{*}{ Coefficient of thermal expansion } & $\mathrm{L}$ & $-2 \times 10^{-6}{ }^{\circ} \mathrm{C}^{-1}$ \\
\cline { 2 - 3 } & $\mathrm{T}$ & $59 \times 10^{-6}{ }^{\circ} \mathrm{C}^{-1}$ \\
\hline
\end{tabular}

L: longitudinal direction, T: Radius direction

\section{Results and discussion}

\subsection{Experimental results}

Raman spectra of a Kevlar 49 single fiber without loading and with loading of $2 \mathrm{GPa}$ tensile stress are shown in Fig. 4. The increase in tensile stress resulted in a clear shift of the spectrum to a lower wavenumber. In this study, a strong band around $1615 \mathrm{~cm}^{-1}$, which corresponds mainly to the phenyl ring/C-C stretching ${ }^{(14)}$, was used to evaluate the stress. To avoid the influence of environment (room temperature, humidity etc), all Raman spectrum used in this study were calibrated using the peak of neon lamp.

The influence of the applied tensile stress on the Raman peak position for a Kevlar 49 single fiber is shown in Fig. 5. Four specimens were tested and each result was shown by the same symbol. A linear decrease in the Raman peak position with an increase in stress was found, irrespective of the specimens. Therefore, the least-squares-fitted straight line for the measured results shown in the figure was used to estimate the tensile stress of the embedded fiber. The slope of the line, which is called the Raman frequency gauge factor (RFGF) ${ }^{(14)}$, was $-3.81 \mathrm{~cm}^{-1} / \mathrm{GPa}$ and this value is between the reported values of -3.46 $\mathrm{cm}^{-1} / \mathrm{GPa}$ by Kawagoe ${ }^{(8)}$ and that of $-4.0 \mathrm{~cm}^{-1} / \mathrm{GPa}$ by Parthenios ${ }^{(14)}$. The maximum difference between the tensile stress and the least-squares-fitted straight line for each specimen was about $0.1 \mathrm{GPa}$. 


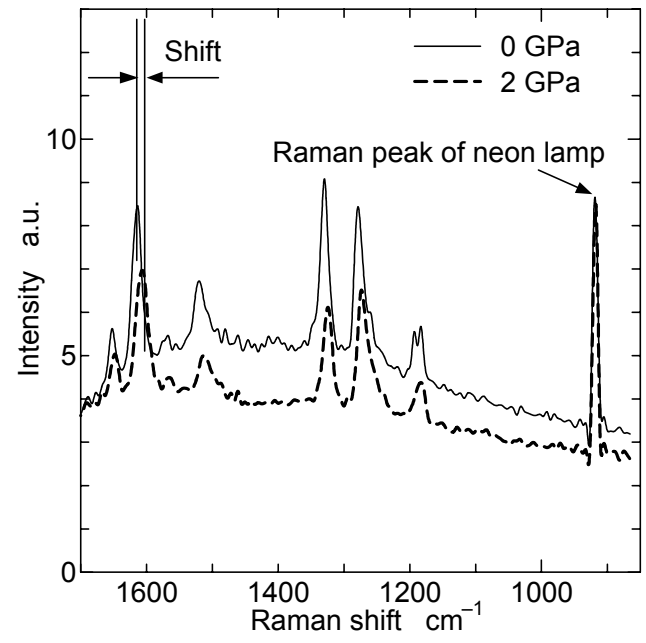

Fig. 4 Examples of the Raman spectrum of Kevlar 49.

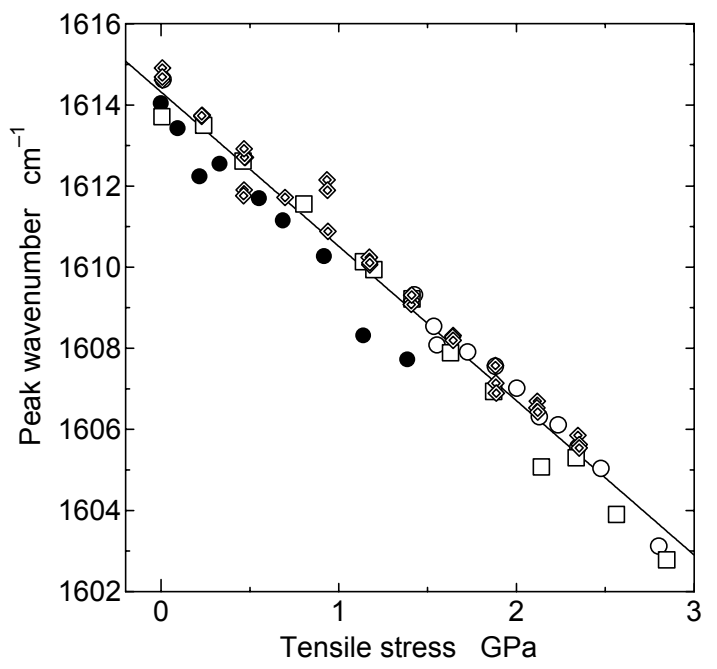

Fig. 5 Relationship between tensile stress of Kevlar 49 single fiber and peak wavenumber.

From the peak wavenumber of Raman spectrum during the pull-out test measured at several stress levels, the axial tensile stress distribution of the fiber was obtained using the calibration line shown in Fig. 5. The results are shown in Fig. 6. The applied nominal stress to the fiber is also plotted in the figure. The origin point of the distance along the fiber is the meniscus point from which the fiber was embedded in the epoxy matrix. The fiber position at the positive value of the distance along the fiber was embedded in the resin matrix as shown in Fig. 2, whereas the fiber at the negative value corresponded to the unembedded free fiber. The stress distribution was measured when the applied stress was $0,0.47,0.94$, 1.41, 1.89 and $2.36 \mathrm{GPa}$. When the applied stress was increased to $2.65 \mathrm{GPa}$, the fiber/matrix interfacial debonding was initiated and propagated, and at the same time the fiber was fractured. After this interfacial debonding, the stress distribution of the fiber in the resin was again measured. In Fig. 6 , the stress measurement accuracy of $\pm 0.1 \mathrm{GPa}$ is also shown by hatching for the applied fiber axial nominal stress. Most of the fiber axial stresses of the unembedded free fiber are within the stress measurement accuracy of $\pm 0.1 \mathrm{GPa}$, which shows that the fiber stress could be measured within accuracy of $\pm 0.1 \mathrm{GPa}$. In addition, the fiber embedded in the matrix had compressive residual stress, which was caused by curing process.

When loading, the fiber stress of the embedded position decreased gradually along the 
fiber from the meniscus point, which means that the stress was transferred from the fiber to the matrix. Considering the fact that the fiber axial stress at the distance of $400 \mu \mathrm{m}$ and that of $500 \mu \mathrm{m}$ were almost equal irrespective of applied stress, the stress transfer length was estimated at about 400-500 $\mu \mathrm{m}$ for the aramid/epoxy system adopted in our study. Other interesting point is that the stress distribution after the fiber/matrix interfacial debonding was different from that before the debonding. The fiber axial stress in the debonded region had the residual tensile stress and had the maximum at the distance of around $200 \mu \mathrm{m}$, although external stress was not applied to the fiber after fiber fracture. The position of the maximum residual stress was close to the position of the interfacial crack tip of $180 \mu \mathrm{m}$, which was confirmed after Raman measurement by using optical microscope.

The debonded specimen was then conditioned in dry air (relative humidity: $20 \%$ ) for $144 \mathrm{~h}$ following by in immersion in deionized water at $80^{\circ} \mathrm{C}$ for $44 \mathrm{~h}$. Raman spectrum were measured during and after these conditionings. Figure 7 shows the influence of conditioning in dry air and successive hot water on the axial fiber stress distribution after debonding. The conditioning in dry air did not affect so much on the stress distribution, but after immersion in hot water the residual stress decreased to almost zero.

Figure 8 shows the effect of conditioning in dry air and successive hot air on the axial fiber stress distribution of another debonded specimen, in which the fiber/matrix interfacial debonding occurred and the fiber was fractured at the same time. The conditioning in dry air at room temperature for 19 days decreased the fiber axial stress little, and after being kept in hot air the residual stress was decreased more. This decrease by conditioning in hot air, however, was smaller than that by conditioning in hot water mentioned before.

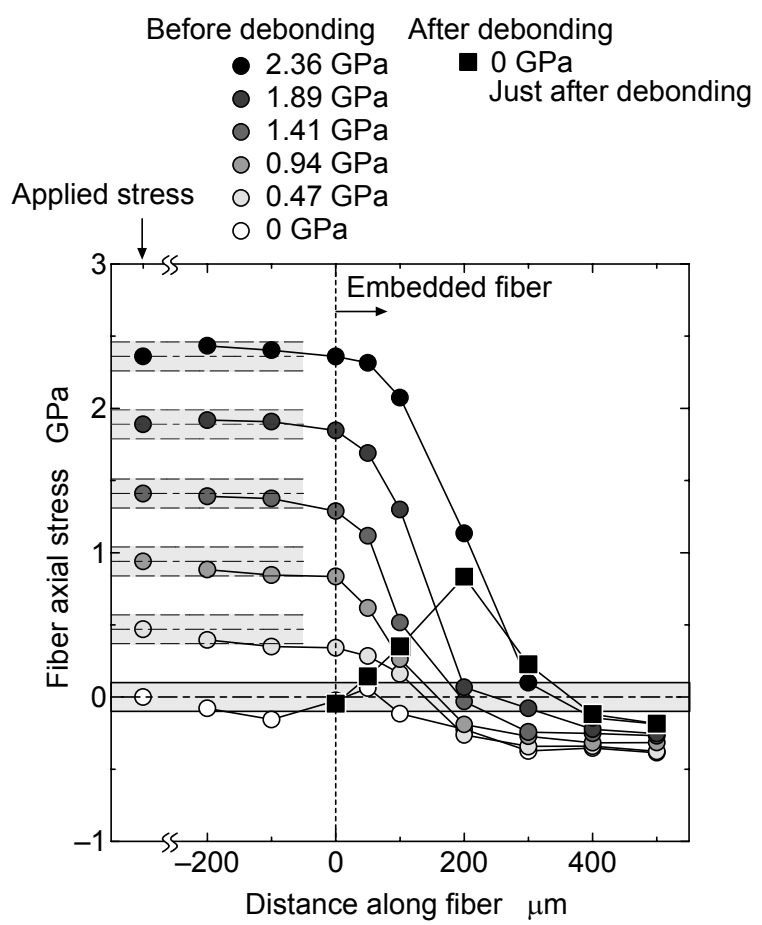

Fig. 6 Fiber axial stress along the fiber during the pull-out test. 


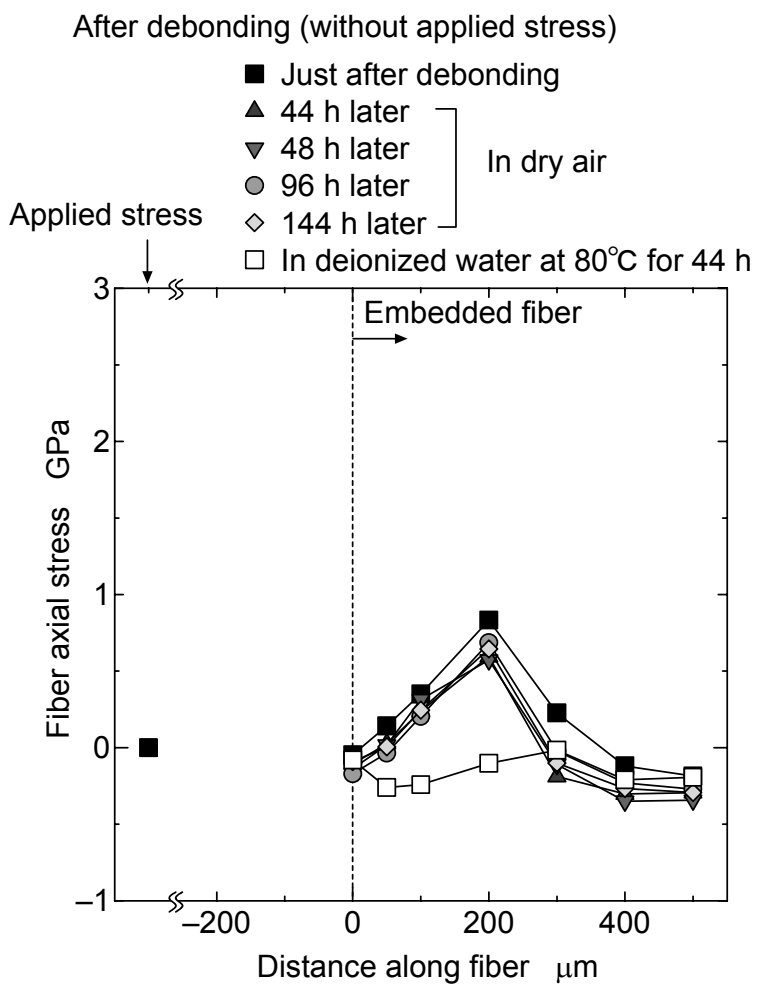

Fig. 7 Influence of conditioning in dry air and successive hot water on the fiber axial stress along the fiber after debonding.

After debonding (without applied stress)

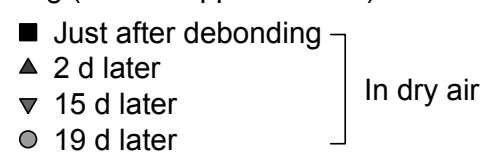

Applied stress $\square$ In air at $80^{\circ} \mathrm{C}$ for $44 \mathrm{~h}$

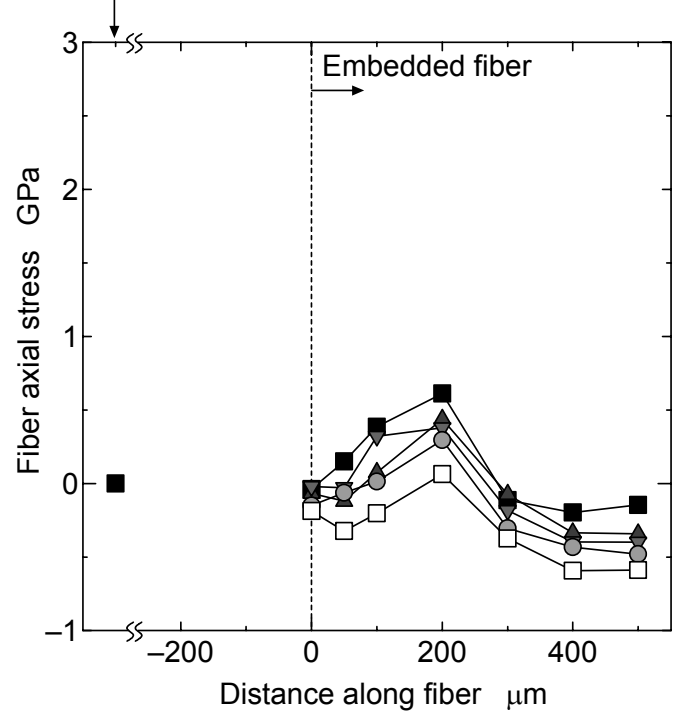

Fig. 8 Influence of conditioning in dry air and successive hot air on the fiber axial stress along the fiber after debonding. 


\subsection{Analytical results and discussion}

The stress distribution without interfacial debonding obtained by the FEM analysis is shown in Fig. 9, with the experimental results shown in Fig. 6. In FEM analysis, the stress of the embedded position decreased gradually along the fiber from the meniscus point and the stresses at the distance along fiber of $500 \mu \mathrm{m}$ are almost the same irrespective of applied stress. This behavior agreed with the experimental results. However, the absolute values obtained by the FEM analysis were not equal to the experimental results, but the embedded fiber had compressive residual stress, which was caused by the difference of the coefficient of thermal expansions of resin and fiber.

Using the FEM model with the interfacial debonding, influence of conditioning in hot water and hot air on the stress distribution was analyzed (Fig. 10). The absolute values of axial fiber stress after interfacial debonding obtained by the FEM analysis were not equal to the experimental results shown in Fig. 7. However, the behavior that the residual stress showed the maximum at around the crack tip of interfacial debonding and another behavior that the residual stress decreased by conditioning in hot air, and decreased more to almost zero by conditioning in hot water, agreed with the experimental results. In order to discuss the influence of conditioning in hot water and hot air, the distribution of the fiber compressive stress to the radius direction at the interface was obtained along the fiber by FEM analysis. The result is shown in Fig. 10. Conditioning in hot air decreased the fiber compressive stress and it became almost zero after conditioning in hot water. This means that the friction force at the interface became smaller or it reached to zero due to a decrease in the compressive stress. In other words, sliding at the interface occurred and the axial fiber tensile residual stress was then released.

Considering the fact that the FEM analysis introducing the friction at the fiber/matrix interface agreed with the experimental results, the fiber axial residual stress was caused by the friction at the interface, which was induced by the difference of the coefficient of thermal expansions of resin and fiber.

In this study, the absolute values obtained by the FEM analysis were not equal to the experimental ones. Following reasons are considered; 1) the boundary condition of FEM analysis is not the same as the sample used, 2) the mechanical properties used in the analysis are the reference data, 3) the plastic deformation was not considered in the analysis, 4) localization of the absorbed water is not introduced in the analysis. However localization of the absorbed water and constitutive equations of the fibers has not yet been clarified. We focus on the fact that the embedded fiber in fiber/matrix debonded area showed the residual stress and by using FEM analysis we investigated the dominant factor that affects the stress distribution during pull-out test. To obtain the quantitative stress distribution, constitutive equations of fiber and resin under each conditions and localized water distribution should be introduced in the FEM analysis. 


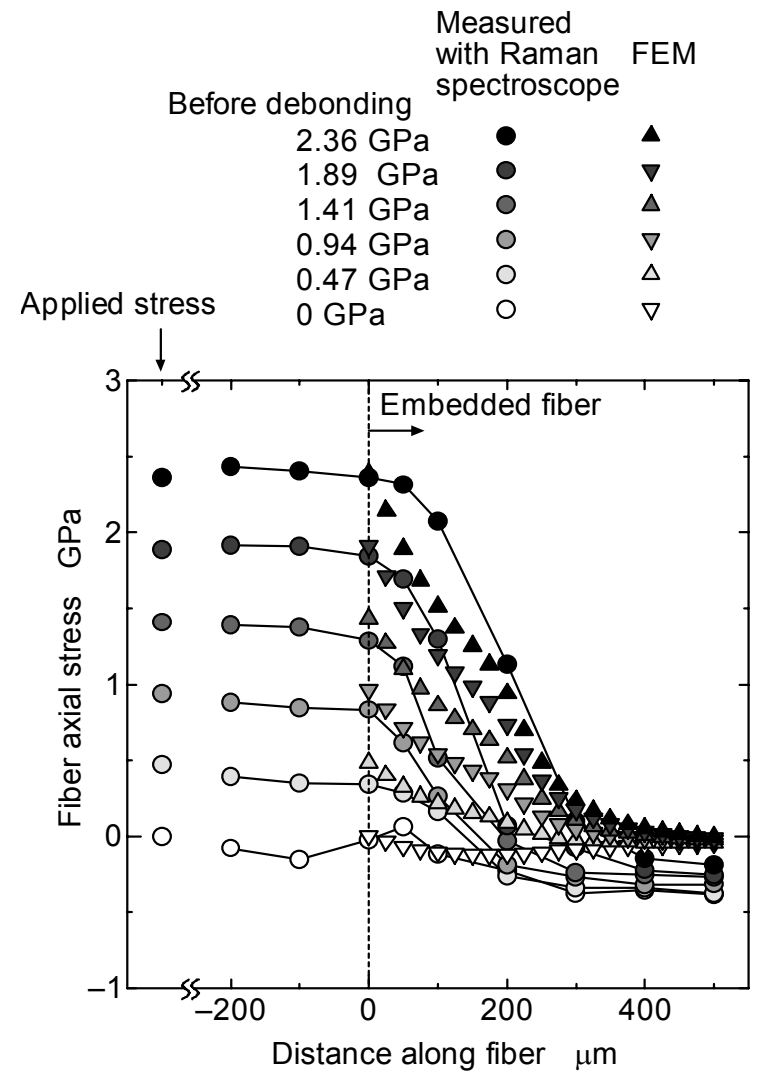

Fig. 9 Fiber axial stress along the fiber during the pull-out test with the results of FEM analysis.

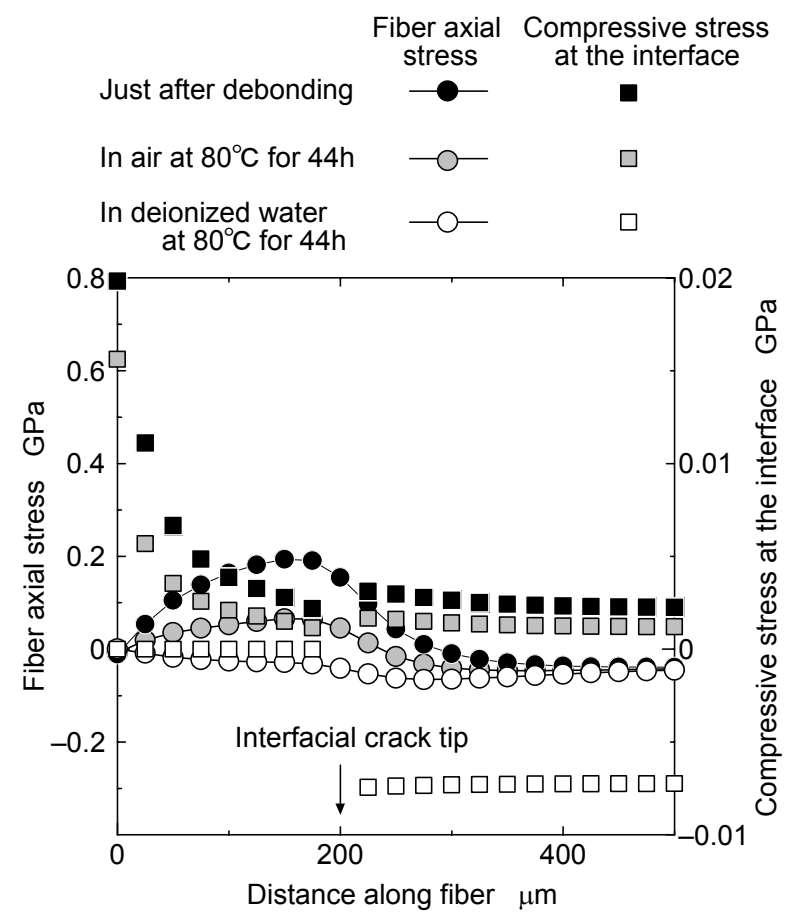

Fig. 10 FEM analysis of the influence of conditioning in hot air and hot water on the fiber axial stress and the compressive stress at the interface along the fiber after debonding. 


\section{Conclusions}

A single-fiber pull-out model composite for an aramid/epoxy system was specially designed and Raman spectroscopy was used to clarify the stress distribution along the fiber before and after the interfacial debonding. In order to understand the factors which affect the distribution of the fiber axial stress, FEM analysis was conducted using 2D model without and with the interfacial debonding. The investigation yielded the following conclusions:

(1) The stress transfer length of the fiber before the interfacial debonding was about 400-500 $\mu \mathrm{m}$.

(2) After fiber/matrix interfacial debonding, the fiber in the debonded region had the axial tensile residual stress, having the maximum at around the interfacial crack tip.

(3) The distribution of axial fiber stress obtained by FEM analysis considering the friction at the fiber/matrix interface agreed with the experimental results. The fiber compressive stress caused by the difference of thermal expansion of resin and fiber induced the friction at the interface. This brought about the residual tensile stress in the fiber even after the external load was not applied.

(4) The residual stress was decreased by a decrease in the fiber compressive stress to the radius direction at the interface, which was caused by the thermal expansion and swelling of the resin.

\section{References}

(1) For example, Komai, K. et al., Cryogenic Temperature and Water Absorption Effects on Mechanical Properties and Fatigue Strength of Carbon Fiber Reinforced Plastics, Transactions of the Japan Society of Mechanical Engineers, Vol.59, No.566 (1993), pp.2278-2285.

(2) Kim, J. K. and Mai, Y. W., Engineered Interfaces in Fiber Reinforced Composites, (1998), Elsevier.

(3) Tanaka, K. et al., Characterization of the Aramid/Epoxy Interfacial Properties by means of Pull-out Test and Influence of Water Absorption, Composites Science and Technology, Vol.62, No.16 (2002), pp. 2167-2174.

(4) Minoshima, K. et al., Characterization of the Propagation of Aramid/epoxy Interfacial Debonding under Fatigue Loading, JSME Mechanical Engineering Congress 2003 Japan, No.03-1 (2003), pp.363-364.

(5) Galiotis, C. et al., The Study of Model Polydiacetylene/epoxy Composites Part.I The Axial Strain in the Fiber, Journal of Materials Science, Vol.19 (1984), pp 3640-3648.

(6) Day, R. J. et al., Surface Modification and its Effect on the Interfacial Properties for Model Aramid-fibre/Epoxy Composites, Composites Science and Technology, Vol.62 (2002), pp.153-166.

(7) Cervenka, A. J. et al., Moisture Absorption and Interfacial Failure in Aramid/Epoxy Composites, Composites, Part A, 29A(1998), pp 1137-1144.

(8) Kawagoe, M. et al., Effect of Water Absorption and Desorption on the Interfacial Degradation in a Model Composite of an Aramid Fibre and Unsaturated Polyester Evaluated by Raman and FT Infra-red Microspectroscopy, Journal of Raman Spectroscopy, 30(1998), pp.913-918.

(9) Miyake, T. et al., Evaluation of Stress Relaxation in a Broken Fiber for a Single Carbon Fiber/Epoxy Composite by Raman Spectroscopy, Transactions of the Japan Society of Mechanical Engineers, Vol.64, No. 620 (1998), pp.981-987.

(10) Patrikis, A. K. et al., Analysis of the Single-Fibre Pull-out Test by means of Raman 
Spectroscopy: PartI. Pull-out of Aramid Fibers from an Epoxy Resin, Composites Science and Technology, Vol.52 (1995), pp.387-396.

(11) Hull, D. and Clyne, T. W., An Introduction to Composite Materials, (1990), Cambridge University Press.

(12) Technical Paper of Curing Agent for Epikote Resin, Japan Epoxy Resins Co. Ltd.

(13) Kawabata, S. et al., Anisotropic Mechanical Properties of Advanced High Performance Fibers Obtained by Single Fiber Testing System, Proceedings of the Ninth International Conference on Composite Materials (ICCM/9), Vol.6 (1993), pp.671-677.

(14) Parthenios, J. et al., Aramid Fibres; a Multifunctional Sensor for Monitoring Stress/Strain Fields and Damage Development in Composite Materials, Engineering Fracture Mechanics, Vol.69 (2002), pp.1067-1087. 